\title{
Toprağa Humik Asit Uygulamasının Mısır Bitkisinin (Zea mays L. indendata) Verim ve Bazı Verim Karakterleri Üzerine Etkisi
}

\author{
Abdullah ÖKTEM ${ }^{1}$ \\ Abdurrahman ÇELİK ${ }^{2}$ \\ ${ }^{1}$ Harran Üniversitesi, Ziraat Fakültesi, Tarla Bitkileri Bölümü, Şanlıurfa \\ ${ }^{2}$ Tarım İl Müdürlüğü, Şanlıurfa \\ $\bowtie$ : aoktem@harran.edu.tr
}

Ayşe Gülgün ÖKTEM ${ }^{1}$

Geliş (Received): 04.11.2017

Kabul (Accepted): 15.12.2017

\begin{abstract}
ÖZET: Bu araştırma, toprağa uygulanan farklı dozlardaki humik asitin, ikinci ürün olarak yetiştirilen mısır (Zea mays L. indendata) bitkisinin verim ve verim unsurları üzerine etkisini belirlemek amacıyla yürütülmüştür. Çalışma, tesadüf blokları deneme desenine göre 3 tekrarlamalı olarak 2012 yılında Harran Ovası, Şanlıurfa koşullarında yürütülmüştür. Bitkisel materyal olarak Motril hibrit mısır çeşidi kullanılmıştır. Humik asit dozları 0 (kontrol), 100 , 200, 300, 400, 500, 600, 700, 800, 900, 1000 ve 1200 ml HA da-1 şeklinde oluşturulmuştur. Humik asit dozları ekim öncesi toprak yüzeyine pülverize edilerek toprağa karıştırılmıştır. Araştırma sonucunda; toprağa uygulanan farklı dozlardaki humik asidin bitki boyu ve sap kalınlığı dışında incelenen özelliklerde istatistiki farklılık oluşturduğu görülmüştür. Bitkideki yaprak sayısında artış olduğu; koçan kalınlığı, koçanda tane ağırlığı, bintane ağırlığı ve tane verimi değerlerinin kontrol uygulamasından itibaren arttığı, $700 \mathrm{ml}$ HA da-1 uygulamasında en yüksek değere ulaşıldığı belirlenmiştir.
\end{abstract}

Anahtar kelimeler: misır, humik asit, topraktan uygulama, Harran Ovası

\section{Effect of Humic Acid Soil Application to Yield and Yield Characteristic of Corn Plant (Zea mays L. indentata)}

\begin{abstract}
This study was aimed to determination of soil treated humic acid effects to yield and yield characteristics of corn plant (Zea mays L. indendata) as grown second crop conditions. Study was set up according to randomized complete experimental design with 3 replicates under Harran Plain conditions in 2012, Şanliurfa. Motril hybrid corn variety was used as a plant material. Humic acid dosages were 0 (control), 100, 200, 300, 400, 500, 600, 700, 800, 900, 1000 and $1200 \mathrm{ml} \mathrm{HA} \mathrm{da-1} \mathrm{for} \mathrm{soil} \mathrm{applications.} \mathrm{Humic} \mathrm{acid} \mathrm{dosages} \mathrm{were} \mathrm{pulverized} \mathrm{to}$ soil surface and mixed before sowing. As a result of research; statistical differences were seen among humic acid soil application dosages in tested characteristics except plant height and stem diameter. Leaf number in plant, ear diameter, kernel weight of ear, thousand weight and grain yield increased with humic acid application. The highest values were obtained from $700 \mathrm{ml} \mathrm{HA} \mathrm{da-1} \mathrm{humic} \mathrm{acid} \mathrm{application.}$

Keywords: Corn, Humic acid, Soil application, Harran Plain
\end{abstract}

\section{GíRiş}

Misır bitkisi birim alanda fazla kuru madde oluşturmakta ve topraktan fazla miktarda besin maddesi kaldırmaktadır. Bitkinin besin maddesi alımı, bitki besin maddelerinin topraktaki miktarı ve durumlarına, iklim ve toprak faktörlerine, yetiştirilen çeşide ve bitkinin gelişim dönemlerine bağlıdır. Çimlenme ve çıkışı izleyen ilk gelişme döneminde mısır bitkisinin yavaş olan besin maddesi alımı, sonraki dönemlerde hızlanmaktadır. Mısır bitkisinde yüksek verim ve kaliteli ürün elde etmek için iyi bir gübreleme yapılması gerekmektedir.

Dünya nüfusunun artışına paralel olarak gıda üretimi ve kimyasal gübre tüketimi her geçen gün hızla artmaktadır. Geleneksel tarım sistemi içerisinde üretim artışına yönelik aşırı miktarda sentetik ve kimyasal girdi kullanımı sonucu çevre kirliliği sorunları ortaya çıkmaktadır. Çevre kirliliği; toprak, bitki, hayvan ve insan arasındaki yaşam zincirindeki tüm canlıları olumsuz yönde etkilemektedir. Ayrıca tarımda kullanılan kimyasal gübreler nedeniyle toprakların kimyasal, fiziksel ve biyolojik özellikleri bozulmaktadır. Bunun yanında fazla miktarda kimyasal gübre kullanımı üreticilerin maliyetini artırmaktadır.

Verim bitkilerin genetik potansiyeline bağlı olmakla birlikte, toprakta bulunan ve toprağa uygulanan besin maddeleri de bu potansiyelin arttırılmasında önemli rol oynamaktadır. Bitkinin toprakta iyi bir gelişim sağlayabilmesi; diğer koşulların yanında önemli derecede yetiştiği toprak ortamının fiziksel, kimyasal ve biyolojik yapısı ile yakından ilişkilidir.

Türkiye'de tarım yapılan arazilerin büyük çoğunluğunda toprağın organik madde seviyesi \% 1'in altındadır. Sürdürülebilir tarım içerisinde hem verim ve kaliteyi artırmak hem de toprağın yapısını iyileştirmek için topraklarımızın organik madde seviyesini yükseltmek gerekmektedir. Topraktaki organik maddenin ana içeriği humus olup, humik asit ise humusun en aktif maddesidir (Kaçar ve Katkat, 2011). Modern tarım sistemlerinde toprağın organik madde seviyesini yükseltmenin en ekonomik ve hılı çözüm yollarından birisi toprağa veya bitkiye doğrudan humik asit uygulanmasıdır. Humik asitler toprakta uzun süre kalmakta ve zaman içinde yavaş yavaş parçalanmaktadır. Humik asit uygulanması ile toprağın havalanması ve su tutması, toprak 
mikroorganizmalarının gelişim ve çoğalması sağlanmakta, bitkilerin stres koşullarına, hastalık ve zararlılara dayanıklılığı artırılmaktadır. Lee ve Bartlett (1976) düşük organik madde içeren topraklara humik asit uygulanması durumunda, misır bitkisi kuru madde miktarında $\% \quad 30-50$ oranında artış saptandığını belirtmektedir. Aydın ve ark. (1998), misır bitkisinin gelişimi, besin elementi alımı ve mineral içeriğine topraktan ve yapraktan uygulanan K-humatın etkisini incelemişlerdir. Araştırmacılar hem topraktan hemde yapraktan misır bitkisine K-humat uygulamasının; doz arttıkça kuru madde miktarını, besin elementi alımını ve bitki mineral içeriğini arttırdığını, ancak topraktan uygulamanın daha etkili olduğunu belirlemişlerdir. Erdal ve ark. (2000), mısır bitkisinde yürüttükleri bir çalışmada, toprağa değişik dozlarda humik asit $(0,250$, $500 \mathrm{mg} \mathrm{kg}^{-1}$ ) uygulamışlardır. Araştırma sonucunda, humik asit uygulamaları ile bitki kuru ağırlığı, bitkinin $\mathrm{Fe}, \mathrm{Zn}$ ve $\mathrm{Mn}$ konsantrasyonlan ile topraktan alınan miktarlarının arttığını belirlemişlerdir. Selçuk ve Tüfenkçi (2009), Van koşullarında mısır bitkisine artan dozlarda humik asit $\left(0,2,4 \mathrm{~L} \mathrm{HA} \mathrm{da}^{-1}\right)$ uygulamalarının koçandaki tane sayısı, koçan boyu, bitki boyu, bin tane ağırlığı ve bitki koçan sayısında önemli düzeyde artış sağladığını belirlemişlerdir.

$\mathrm{Bu}$ çalışma, farklı dozlarda toprağa uygulanan humik asitin Harran Ovası koşullarında ikinci ürün olarak yetiştirilen atdişi mısırın verim ve verim unsurları üzerine etkisini belirlemek amaciyla yürütülmüştür.

\section{MATERYAL ve YÖNTEM}

Araştırma, 2012 yılında Harran Ovası koşullarında yürütülmüştür. Araştırmanın yürütüldüğü toprak ana materyali alüviyal, derin profilli olup, İkizce serisi toprakları içerisindedir. Tüm profilin kireç ve potasyum oranı yüksek olup, buna karşılık fosforca fakirdir. Deneme alanından alınan toprak örnekleri analiz sonuçlarına ait bazı fiziksel ve kimyasal özellikler Çizelge 1'de verilmiştir.

Şanlıurfa, Güneydoğu Anadolu iklim bölgesine dâhil olmakla beraber, Akdeniz ikliminin etkisi altındadır. Yazları sıcak ve kurak kışları ise 1lık olan bir iklim özelliği göstermektedir. Şanlıurfa ili 2012 yaz döneminde denemenin yürütüldüğü aylara ait uzun yıllar ve aylık ortalama iklim verileri Çizelge 2'de verilmiştir. Çizelge 2.'den görüldüğü gibi denemenin yürütüldüğü 2012 yılı ile uzun yıllar iklim değerleri birbirlerine yakın seyretmiştir. Yaz aylarında en yüksek sıcaklık değerleri 40 derecenin üzerinde gerçekleşmiş, yağış ise yok denecek kadar çok düşük seviyede kalmıştır.

Çizelge 1. Deneme alanı topraklarına ait bazı fiziksel ve kimyasal özellikler

\begin{tabular}{llllllllllll}
\hline $\begin{array}{l}\text { Derinlik } \\
(\mathrm{cm})\end{array}$ & $\begin{array}{l}\text { Organik } \\
\text { Madde (\%) }\end{array}$ & $\begin{array}{l}\text { Toplam } \\
\text { Tuz (\%) }\end{array}$ & $\mathrm{pH}$ & $\begin{array}{l}\text { Kireç } \\
(\%)\end{array}$ & $\begin{array}{l}\mathrm{P}_{2} \mathrm{O}_{5} \\
\mathrm{~kg} \mathrm{da}^{-1}\end{array}$ & $\begin{array}{l}\mathrm{K}_{2} \mathrm{O} \\
\mathrm{kg} \mathrm{da}^{-1}\end{array}$ & $\begin{array}{l}\mathrm{Fe} \\
\mathrm{ppm}\end{array}$ & $\begin{array}{l}\mathrm{Zn} \\
\mathrm{ppm}\end{array}$ & \multicolumn{2}{c}{ Tekstür (\%) } \\
\hline $0-20$ & 0.78 & 0.098 & 7.7 & 25.4 & 3.6 & 99.3 & 2.11 & 0.46 & 24.16 & 53.84 & 22.0 \\
\hline
\end{tabular}

Çizelge 2. Şanlıurfa ili 2012 yaz döneminde denemenin yürütüldüğü aylara ait uzun yıllar ve aylık ortalama iklim verileri (Anonim, 2012)

\begin{tabular}{|c|c|c|c|c|c|c|c|}
\hline AYLAR & Yillar & $\begin{array}{l}\text { Ortalama } \\
\text { sicaklik } \\
\left({ }^{0} \mathrm{C}\right)\end{array}$ & $\begin{array}{c}\text { En yüksek } \\
\text { sicaklik } \\
\left({ }^{0} \mathrm{C}\right)\end{array}$ & $\begin{array}{c}\text { En düşük } \\
\text { sıcaklık } \\
\left.{ }^{0} \mathrm{C}\right)\end{array}$ & $\begin{array}{l}\text { Ort. nispi } \\
\text { Nem } \\
(\%)\end{array}$ & $\begin{array}{c}\text { Güneşlenme } \\
\text { süresi } \\
\text { (Saat) }\end{array}$ & $\begin{array}{l}\text { Yağış } \\
\text { toplamı } \\
\left(\mathrm{kg} / \mathrm{m}^{2}\right)\end{array}$ \\
\hline \multirow{2}{*}{ Mayıs } & 2012 & 22.4 & 33.2 & 13.0 & 40.8 & 8.6 & 42.3 \\
\hline & Uzun yil ort. & 22.3 & 40.0 & 6.7 & 41.4 & 10.6 & 25.7 \\
\hline \multirow{2}{*}{ Haziran } & 2012 & 30.6 & 42.2 & 17.6 & 21.2 & 11.9 & 5.8 \\
\hline & Uzun yil ort. & 28.2 & 44.0 & 12.3 & 34.5 & 12.1 & 3.6 \\
\hline \multirow{2}{*}{ Temmuz } & 2012 & 33.3 & 44.2 & 20.0 & 18.8 & 12.0 & 0.2 \\
\hline & Uzun yil ort. & 32.0 & 46.8 & 16.2 & 30.7 & 12.1 & 0.7 \\
\hline \multirow{2}{*}{ Ağustos } & 2012 & 32.3 & 42.1 & 22.4 & 29.0 & 10.8 & 0.2 \\
\hline & Uzun yil ort. & 31.2 & 44.8 & 16.9 & 45.6 & 11.2 & 1.1 \\
\hline \multirow{2}{*}{ Eylül } & 2012 & 28.4 & 39.9 & 15.6 & 28.0 & 9.6 & 2.0 \\
\hline & Uzun yil ort. & 26.8 & 42.0 & 11.3 & 40.7 & 10.6 & 3.2 \\
\hline \multirow{2}{*}{ Ekim } & 2012 & 21.0 & 37.0 & 11.6 & 48.5 & 6.1 & 35.2 \\
\hline & Uzun yil ort. & 20.3 & 36.4 & 3.8 & 59.6 & 7.4 & 25.3 \\
\hline \multirow{2}{*}{ Kasım } & 2012 & 14.9 & 26.9 & 7.1 & 65.6 & 4.2 & 68.4 \\
\hline & Uzun yil ort. & 12.5 & 29.2 & -2.7 & 65.2 & 5.5 & 46.3 \\
\hline
\end{tabular}

Çalışmada, bitkisel materyal olarak Motril hibrit mısır çeşidi, humik asit kaynağı olarak \%12 humik asit içeren solüsyon kullanılmıştır. Ekimden önce toprak pullukla derin sürülmüş, kültivatör ve goble-disk çekilerek toprak ufalanmış, tapan çekilerek düzlenmiş ve ekime hazır hale getilmiştir. Araştırma tesadüf blokları deneme desenine göre üç tekrarlamalı olarak kurulmuştur. Her parsel 4 siradan oluşturulmuş ve parsel boyu $5 \mathrm{~m}$ olarak alınmıştır. Topraktan humik asit dozlar1 0 (kontrol), 100, 200, 300, 400, 500, 600, 700, 
$800,900,1000$ ve $1200 \mathrm{ml} \mathrm{HA} \mathrm{da}^{-1}$ şeklinde uygulanmıştır. Belirtilen humik asit dozları ekim öncesi toprak yüzeyine pülverize edilerek toprağa karıştırılmıştır. Dekara saf olarak $24 \mathrm{~kg}$ azot, $8 \mathrm{~kg}$ fosfor $\left(\mathrm{P}_{2} \mathrm{O}_{5}\right)$ esas alınarak, azotun $8 \mathrm{~kg}$ ile fosforun tamamı ekimle birlikte, azotun kalan $16 \mathrm{~kg}$ ise bitkiler $40 \mathrm{~cm}$ boylandığında banda uygulanmıştır. Sıra arası $70 \mathrm{~cm}$ ve sıra üzeri $20 \mathrm{~cm}$, ekim derinliği $5-6 \mathrm{~cm}$ olacak şekilde ekim yapılmıştır. Ekimden sonra iyi bir çıkışın sağlanması için yağmurlama sulama sistemiyle tav sulaması yapılmıştır. Daha sonraki sulamalar karık sulama sistemi ile yapılmıştır.

Vejetasyon süresi boyunca traktör ve el çapası yapılmış olup, yabancı ot mücadelesi için Ekipp (\%30 Foramsulfuron $+\% 1$ lodosulfuron-methyl-sodium + $\% 30$ Isoxadifen-ethyl etkili maddeli) isimli herbisit $25 \mathrm{~g}$ $\mathrm{da}^{-1}$ dozunda misirın 2-6 yapraklı olduğu dönemde kullanılmıştır. Her bir parselden rastgele seçilen 10 örnek üzerinde bitkisel ve koçan özellikleri belirlenmiştir. Bitkiler tamamen sararıp kuruduğunda hasat işlemi elle yapılmıştır. Her parselde tane nemi belirlenmiş ve parsel verimleri \%15 neme göre düzeltilmiştir. Elde edilen veriler kullanılarak varyans analizi yapılmış ve ortalamalar Duncan testine göre grublandırılmıştır.

\section{BULGULAR ve TARTIŞMA \\ Yaprak Sayısı (adet bitki ${ }^{-1}$ )}

Yapılan varyans analizi sonucuna göre humik asit dozları arasında bitkide yaprak sayısı yönünden istatistiki önemli düzeyde bir farklılık olduğu belirlenmiştir $(\mathrm{P} \leq 0.01)$. Çizelge 3 'den görüldüğü gibi yaprak sayıs1 11.23 ile 15.10 adet bitki ${ }^{-1}$ arasında değişmiştir. En düşük bitki sayısı 11.23 adet bitki ${ }^{-1}$ ile kontrol uygulamasından, en yüksek bitki sayısı ise 15.10 adet bitki ${ }^{-1}$ ile $700 \mathrm{ml} \mathrm{da} \mathrm{da}^{-1}$ humik asit uygulamasından elde edilmiştir. Bitkide yaprak sayısının artması ile bitkide fotosentez etkinliğinin arttığı, bunun ise tane verimine olumlu katkı sağladığ söylenebilir. Bitkide yaprak sayısı $600 \mathrm{ml} \mathrm{da}^{-1}$ humik asit uygulamasına kadar artmış, bundan sonraki 600 ile $1200 \mathrm{ml} \mathrm{da}^{-1}$ humik asit uygulamaları arasında istatistiki farklılık görülmemiştir. Humik asitin bitki gelişimine pozitif etki yaptığı bulgularımızı destekleyen bazı araştırıcılar tarafindan da bildirilmektedir (Bozoğlu ve ark. 2004; Day ve ark. 2011).

\section{Bitki Boyu (cm)}

Varyans analizi sonucuna göre humik asit dozları arasında bitki boyu açısından istatistiki olarak önemli düzeyde bir farklılık bulunmamıştır. Bitki boyu değerleri $228.3 \mathrm{~cm}$ ile $231.3 \mathrm{~cm}$ arasında değişmiştir. Çizelge 3'de görüldüğü gibi en yüksek bitki boyu 700 $\mathrm{ml} \mathrm{da}{ }^{-1}(231.3 \mathrm{~cm})$ humik asit dozunda, en düşük bitki boyu ise humik asit uygulanmamış parsellerden elde edilmiştir $(228.3 \mathrm{~cm})$. İstatistiki düzeyde olmasa da artan humik asit uygulamaları ile birlikte bitki boyunun azda olsa arttığ gözlenmektedir. Benzer bulgular Padem (1998) tarafından da bildirilmektedir. Selçuk ve Tüfenkçi (2009) Van koşullarında mısır bitkisine uyguladıkları humik asidin bitki boyunu önemli düzeyde etkilediğini bildirmişlerdir.

Çizelge 3. Toprağa uygulanan farklı dozlardaki humik asitin mısır bitkisinde bitkide yaprak sayısı, bitki boyu, sap kalınlığı, koçan kalınlığı, koçanda tane ağırlığı, bin tane ağırlığı ve tane verimi değerleri ile oluşan istatistiki gruplar

\begin{tabular}{|c|c|c|c|c|c|c|c|}
\hline $\begin{array}{l}\text { Humikasit } \\
\text { dozlar1 } \\
\left(\mathrm{ml} \mathrm{da}^{-1}\right)\end{array}$ & $\begin{array}{l}\text { Yaprak } \\
\text { sayısı } \\
(\text { adet bitki-1) }\end{array}$ & $\begin{array}{l}\text { Bitki boyu } \\
(\mathrm{cm})\end{array}$ & $\begin{array}{l}\text { Sap } \\
\text { kalınlığ1 } \\
(\mathrm{mm})\end{array}$ & $\begin{array}{l}\text { Koçan } \\
\text { kalınlığg1 } \\
(\mathrm{mm})\end{array}$ & $\begin{array}{l}\text { Koçanda } \\
\text { tane } \\
\text { ağırlığı (g) }\end{array}$ & $\begin{array}{l}\text { Bin tane } \\
\text { ağırliğ́ } \\
(\mathrm{g})\end{array}$ & $\begin{array}{l}\text { Tane } \\
\text { verimi } \\
\left(\mathrm{kg} \mathrm{da}^{-1}\right)\end{array}$ \\
\hline 0 & $11.23 \mathrm{e}^{\dagger}$ & 228.3 & 19.47 & $41.53 \mathrm{~d}$ & $136.67 \mathrm{~d}$ & $365.0 \mathrm{f}$ & $962.6 \mathrm{f}$ \\
\hline 100 & $11.73 \mathrm{e}$ & 228.3 & 19.50 & $41.74 \mathrm{~cd}$ & $160.00 \mathrm{c}$ & $370.3 \mathrm{e}$ & $1109.7 \mathrm{e}$ \\
\hline 200 & $12.27 \mathrm{~d}$ & 229.0 & 19.57 & $41.85 \mathrm{~cd}$ & $160.00 \mathrm{c}$ & $380.7 \mathrm{~d}$ & $1138.1 \mathrm{de}$ \\
\hline 300 & $12.58 \mathrm{~d}$ & 230.0 & 19.63 & $42.08 \mathrm{bcd}$ & $163.33 \mathrm{bc}$ & $381.7 \mathrm{~cd}$ & $1158.3 \mathrm{cde}$ \\
\hline 400 & $13.13 \mathrm{c}$ & 230.0 & 19.63 & $42.22 \mathrm{bcd}$ & $170.00 \mathrm{bc}$ & $383.0 \mathrm{~cd}$ & $1233.0 \mathrm{bcd}$ \\
\hline 500 & $13.98 \mathrm{~b}$ & 231.0 & 19.73 & $42.33 \mathrm{abcd}$ & $176.67 \mathrm{~b}$ & $389.0 \mathrm{~b}$ & $1245.4 \mathrm{bc}$ \\
\hline 600 & $14.95 \mathrm{a}$ & 231.0 & 19.75 & $42.77 \mathrm{ab}$ & $176.67 \mathrm{~b}$ & $389.0 \mathrm{~b}$ & $1278.9 \mathrm{~b}$ \\
\hline 700 & $15.10 \mathrm{a}$ & 231.3 & 19.80 & $43.09 \mathrm{a}$ & $196.67 \mathrm{a}$ & $399.0 \mathrm{a}$ & $1383.1 \mathrm{a}$ \\
\hline 800 & $14.99 \mathrm{a}$ & 230.7 & 19.73 & $42.58 \mathrm{abc}$ & $176.67 \mathrm{~b}$ & $397.7 \mathrm{a}$ & $1258.7 \mathrm{~b}$ \\
\hline 900 & $14.83 \mathrm{a}$ & 230.7 & 19.73 & $42.30 \mathrm{abcd}$ & $176.67 \mathrm{~b}$ & $389.7 \mathrm{~b}$ & $1237.7 \mathrm{bc}$ \\
\hline 1000 & $14.83 \mathrm{a}$ & 230.0 & 19.70 & $42.28 \mathrm{abcd}$ & $170.00 \mathrm{bc}$ & $384.7 \mathrm{c}$ & $1216.3 \mathrm{bcd}$ \\
\hline 1200 & $14.80 \mathrm{a}$ & 229.7 & 19.63 & $42.13 \mathrm{bcd}$ & $170.00 \mathrm{bc}$ & $384.7 \mathrm{c}$ & $1210.0 \mathrm{bcd}$ \\
\hline Ortalama & 13.698 & 230.0 & 19.66 & 42.24 & 157.17 & 384.53 & 1202.64 \\
\hline LSD & 0.509 & - & - & 0.852 & 14.33 & 3.152 & 96.391 \\
\hline Önemlilik & $* *$ & öd & öd & $*$ & $* *$ & $* *$ & $* *$ \\
\hline
\end{tabular}

öd: önemli değil, *: \% 5, **: \% 1'e göre önemli

$\dagger$ : Aynı harf grubunda yer alan ortalamalar arasında Duncan testine göre 0.05 düzeyde istatistikî olarak önemli farklılik yoktur.

\section{Sap Kalınlı̆̆ $\mathbf{~ ( m m ) ~}$}

Humik asit dozları arasında sap kalınlığı açısından istatistiki olarak önemli düzeyde bir farklılık bulunmamıştır. En yüksek sap kalınlığı 19.80 mm ile
$700 \mathrm{ml} \mathrm{da} \mathrm{d}^{-1}$ humik asit uygulamasında, en düşük sap kalınlığı ise, $19.46 \mathrm{~mm}$ ile 0 (kontrol) uygulamasından elde edilmiştir (Çizelge 3). Sap kalınlığı değerlerinde istatistiki olmasada kontrole göre artış gözlenmiştir. 
Padem (1998) topraktan humik asit kullanımının sap kalınlığını önemli düzeyde etkilediğini bildirmiştir.

\section{Koçan Kalınlı̆̆ $\mathbf{~ ( m m ) ~}$}

Çizelge 3'den görüldüğü gibi koçan kalınlığı yönünden toprağa uygulanan humik asit dozları arasında istatistiki önemlilik düzeyinde farklılık saptanmıştır $(\mathrm{P} \leq 0.05)$. Koçan kalınlığı $41.53 \mathrm{~mm}$ ile $43.09 \mathrm{~mm}$ arasında değişmiştir. En yüksek koçan kalınlığı değeri 43.09 mm ile $700 \mathrm{ml} \mathrm{da}^{-1}$ toprağa humik asit uygulamasında ölçülmüş; en düşük koçan kalınlığı ise $41.53 \mathrm{~mm}$ ile 0 (kontrol) parsellerinden elde edilmiştir. Humik asit koçan kalınlığı üzerine olumlu etkide bulunmuştur. Bulgularımızla uyumlu olarak humik asit'in bitkisel özellikleri olumlu etkilediği Aydın ve ark. (1998), Erdal ve ark. (2000) ile Selçuk ve Tüfenkçi (2009) tarafindan da belirtilmektedir.

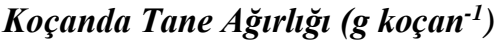

Varyans analizi sonucuna göre; humik asit dozları arasında koçanda tane ağırlığı yönünden istatistiki olarak önemli düzeyde farklılık bulunduğu gözlenmiştir $(\mathrm{P} \leq 0.01)$. Çizelge 3 'de görüldüğü gibi koçanda tane ağırlığı değerleri 136.66 ile $196.66 \mathrm{~g} \mathrm{koçan}^{-1}$ arasında değişmiştir. Aynı çizelgeden, en yüksek koçanda tane ağırlığının $700 \mathrm{ml} \mathrm{da}^{-1}$ humik asit uygulamasında, en düşük koçanda tane ağırlığının ise 136.66 g koçan $^{-1}$ ile kontrol parselinden elde edildiği görülmektedir. Artan humik asit dozlarının koçanda tane ağırlığını artırdığ belirlenmiştir. Benzer şekilde humik asitin tane ağırlığını artırdığı Ören ve Başal (2005) tarafindan da belirtilmektedir.

\section{Bin Tane Ăğırliğı (g)}

Bin tane ağırlığı yönünden humik asit dozları arasında istatistiki düzeyde önemli $(\mathrm{P} \leq 0.01)$ farklılık olduğu yapılan varyans analizi ile saptanmıştır. Bin tane ağırlığ değerleri 365 g ile $399 \mathrm{~g}$ arasında değişmiştir. Çizelge 3 'den görüldüğü gibi en yüksek bin tane ağırlığ 1 değerinin $399 \mathrm{~g}$ ile $700 \mathrm{ml} \mathrm{da}{ }^{-1}$ toprağa humik asit uygulamasından elde edildiği ve $800 \mathrm{ml} \mathrm{da}^{-1}$ humik asit uygulamasıyla arasında istatistiki fark oluşmadığı izlenebilmektedir. En düşük bin tane ağırlığı ise $365 \mathrm{~g}$ ile 0 humik asit (kontrol) parsellerinden elde edildiği görülmektedir. Bu durum, bin tane ağırlığının toprağa uygulanan humik asit dozlarından pozitif olarak etkilendiğini göstermektedir. Sonuçlarımızı destekler nitelikte Selçuk ve Tüfekçi (2009) ile Ören and Başal (2005) bin tane ağırlığının humik asitten olumlu etkilendiğini bildirmişlerdir.

\section{Tane Verimi ( $\mathrm{kg} \mathrm{da^{-1 } )}$}

Varyans analizi sonucuna göre; dekara tane verimi yönünden humik asit dozları arasında istatistiki olarak önemli düzeyde farklılık saptanmıştır $(\mathrm{P} \leq 0.01)$. Tane verimi $962.61 \mathrm{~kg} \mathrm{da}^{-1}$ ile $1383.04 \mathrm{~kg} \mathrm{da}^{-1}$ arasında değişmiştir. Çizelge 3'den görüldüğü gibi $700 \mathrm{ml} \mathrm{da}^{-1}$ humik asit dozunda (1383.04 $\mathrm{kg} \mathrm{da}^{-1}$ ) en yüksek, 0 (kontrol) humik asit dozunda $\left(962.61 \mathrm{~kg} \mathrm{da}^{-1}\right)$ ise en düşük tane verimi elde edilmiştir (Şekil 1). Tane verimi humik asitten olumlu yönde etkilenmiştir. Tane verimi kontrol uygulamasından itibaren $700 \mathrm{ml} \mathrm{da}^{-1}$ humik asit dozuna kadar artış göstermiş, bütün humik asit dozları kontrol uygulamasından daha yüksek tane verimi değerleri vermiştir. Bulgularımızı destekler nitelikte bazı araştırıcılar (Aydın ve ark., 1998; Erdal ve ark., 2000; Çimrin ve ark., 2001; Ören ve Başal, 2005) humik asit uygulamalarının verimi olumlu yönde etkilediğini, Bozoğlu ve ark. (2004) \%12'lik humik asit uygulaması ile verimin arttığını bildirmişlerdir.

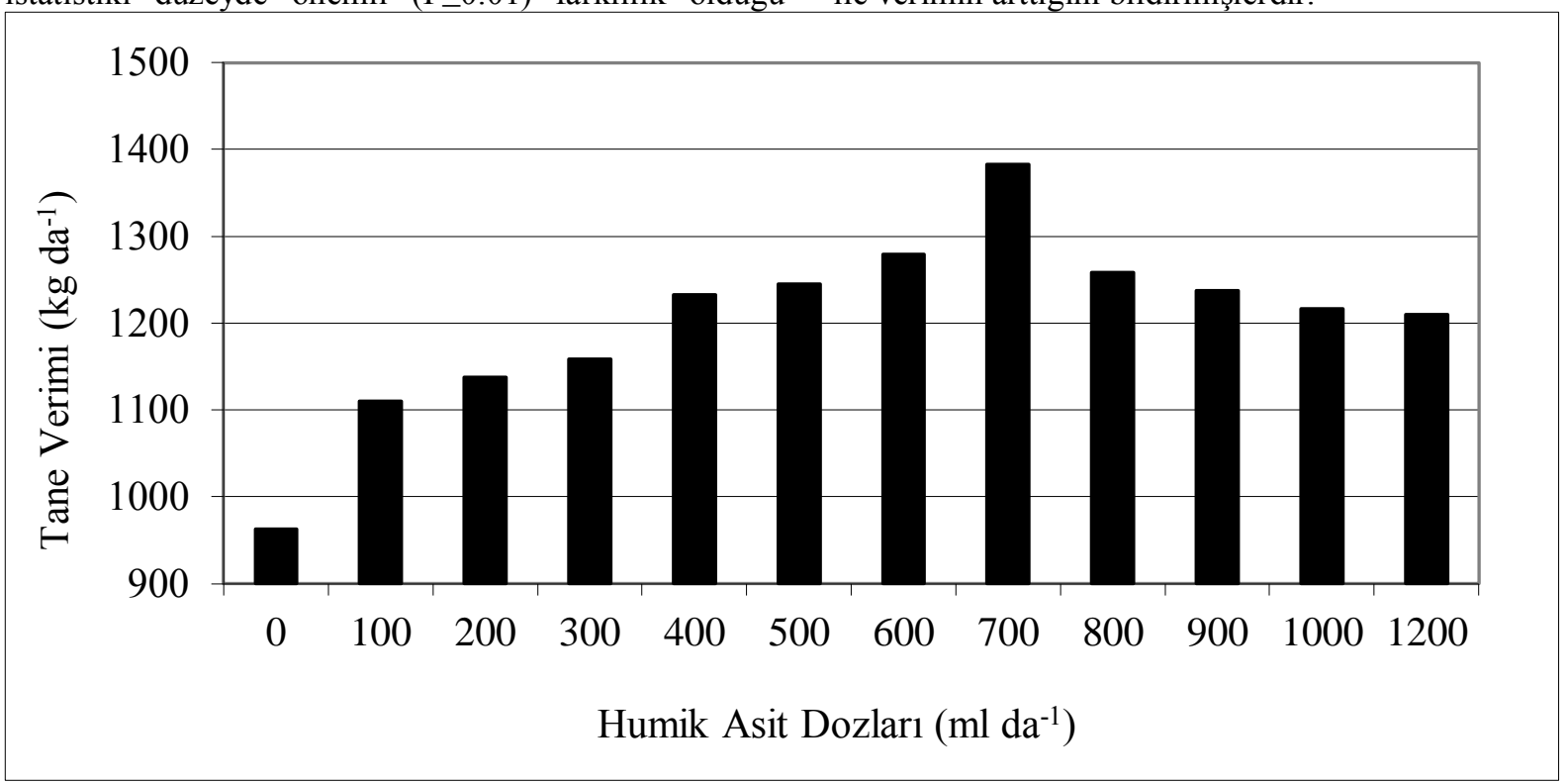

Şekil 1.Toprağa humik asit uygulamasında elde edilen tane verimi değerleri $\left(\mathrm{kg} \mathrm{da}^{-1}\right)$

\section{SONUÇ}

Toprağa humik asit uygulamasıyla; bitkideki yaprak sayısında artış olduğu, bitki boyu, sap kalınlığ 1 , koçan boyu, koçan kalınlığı, koçanda tane a ğırlığı, bintane ağırlığı ve tane veriminde kontrol uygulamasından itibaren değerlerin arttığı, en yüksek değerlere $700 \mathrm{ml}$ $\mathrm{da}^{-1}$ uygulamasında ulaşıldığı belirlenmiştir

KAYNAKLAR

Anonim 2012. Şanlıurfa Meteoroloji İstasyonu İklim Değerleri, Şanlıurfa. 
Aydın A, Turan M, Sezen Y 1998. Effect of fulvic+humic Acid Application on Yield and Nutrient Uptake in Sunflower and Corn. Improved Crops Quality by Nutrient Management. Kluver Acedemic Publishers Dordrecth, Boston, London p.249-252.

Çimrin KM, Karaca S, Bozkurt MA 2001. Misır Bitkisinin Gelişimi ve Beslenmesi Üzerine Humik Asit ve NPK Uygulamalarının Etkisi. Tarım Bil. Dergisi, 7 (2): 95-100.

Bozoglu H, Pekşen E, Gülümser A 2004. Sıra Aralığg ve Potasyum Humat Uygulamasinın Bezelyenin Verim ve Bazı Özelliklerine Etkisi. A.Ü. Tarım Bil. Dergisi, 10(1): 53-58.

Erdal İ, Bozkurt MA, Çimrin KM 2000. Hümik Asit ve Fosfor Uygulamalarının Misır Bitkisinin (Zea mays L.) $\mathrm{Fe}, \mathrm{Zn}, \mathrm{Mn}$ ve $\mathrm{Cu}$ İçeriği Üzerine Etkisi. Tarım Bilimleri Dergisi, 6 (3): 91-96.

Ören Y, Başal H 2005. Humik Asit ve Çinko (Zn) Uygulamalarının Pamukta (Gossypium Hirsutum L.) Verim, Verim Komponentleri ve Lif Kalite
Özelliklerine Etkisi. ADÜ Ziraat Fakültesi Dergisi, 3(2): $77-83$

Kaçar B, Katkat V 2011. Bitki Besleme. Nobel yayınevi, Ankara, $678 \mathrm{~s}$.

Lee YS, Bartlett RJ 1976. Stimulation of Plant Growth by Humic Substances. Soil Sci. Soc. Am. J., 40: 876-879.

Padem H 1998. Humik Asit Katkılı Yaprak Gübresi Uygulamasının Hıyarda (Cucumis sativus L.) Fide Kalitesi ve Besin Elementi İçeriğine Etkisi. SDÜ. Fen Bil. Dergisi, 3(1): 27-41.

Selçuk R, Tüfenkçi Ş 2009. Artan Dozlarda Çinko ve Humik Asit Uygulamalarının Misırın Verim ve Besin İçeriğine Etkisi. Yüzüncü Y1l Üniv. Fen Bil. Enst. Yük. Lis. Tezi, Van.

Day S, Kolsarıc1 O, Kaya M 2011. Hümik Asit Uygulamaları Zamanı ve Dozlarının Ayçiceğinde (Helianthus annuus) Verim, Verim Öğeleri ve Yağ Oranına Etkisi. Akdeniz Universitesi Ziraat Fakultesi Dergisi, 24 (1): 33-37. 